\title{
Retrospective Study to Explore a New Predictor for the Early Diagnosis of Perforated Acute Appendicitis
}

\author{
Shaker AM1*, Malik A² and Akram B ${ }^{3}$ \\ ${ }^{1}$ Department of General Surgery, East Jeddah Hospital, Ministry of Health, Jeddah, \\ Kingdom of Saudi Arabia \\ ${ }^{2}$ King salman hospital MOH Riyadh, Kingdom of Saudi Arabia \\ ${ }^{3}$ King Fahad hospital Jeddah, Kingdom of Saudi Arabia
}

\section{Research Article}

Volume 3 Issue 1

Received Date: November 26, 2018

Published Date: January 09, 2019

DOI: $10.23880 /$ mjccs-16000195

*Corresponding author: Shaker A Majrashi, Department of General Surgery, East Jeddah Hospital, Ministry of Health, Jeddah, Kingdom of Saudi Arabia, Email: shaker7744@hotmail.com

\section{Abstract}

Background: Acute appendicitis (AA) is one of the most common indications for emergency abdominal surgery.

Objective: To assess diagnostic and prognostic role of serum bilirubin in the management and diagnosis of acute appendicitis, as well as confirming the relationship between them.

Methods: A data has been collected about Patients diagnosed with acute appendicitis male and females from the age of 4 up to 80 among king Fahad hospital and East Jeddah hospital during the period from $1^{\text {st }}$ Jan 2012 up to $30^{\text {th }}$ July 2017, with sample size of 888 patients.

Results: The study was comprised of 888 consecutive patients. Significance was confirmed as P-value $<0.05$ Significance was found upon analyzing direct bilirubin for all age groups, total bilirubin for age group less than 15 years, direct bilirubin for 15-20 and 21-30 age groups.

Conclusions: Our investigation confirms that bilirubin level might be a biomarker for having appendicitis, it can occasionally differentiate between types of appendicitis, but this is not a sharp ending as it has no role in patients within age groups of above 30 years. However, a problem of specificity is present which hinders the adoption of serum bilirubin as a biomarker foe AA. In addition, several other methods are more specific for the diagnosis and treatment regimen through suitable surgery procedure.

Keywords: Appendectomy; Appendicectomy; Appendicitis; Bilirubin 


\section{Medical Journal of Clinical Trials \& Case Studies}

Abbreviations: AA: Acute Appendicitis; WBC: White Blood Cells Count; CRP: C-Reactive Protein; CT: Computed Tomography.

\section{Introduction}

The analysis of inflamed appendix in its acute condition which is called appendicitis can be tested, and postponed determination may prompt extreme inconveniences. For example, aperture and peritonitis, which are related with high severity. Serum markers, for example, white blood cells count (WBC), C-Reactive Protein (CRP), serum bilirubin, and liver transaminase levels have been proposed as individual markers for an infected appendix and appendiceal aperture [1,2].

In current practice, the analysis of an infected or inflamed appendix in its acute conditions is primarily clinical, upheld by research centre and imaging examinations. Computed tomography (CT) and Ultrasonography may raise the indicative affectability or in other words, sensitivity to $66-100 \%$ and $90-100 \%$, individually, however these practices which are resembled with imaging involve a few disadvantages, for example, cost, radiation presentation, and dependency of the operator [3]. As of now, no single clinical or research facility test can decide whether a patient has an inflamed ruptured appendix. The surgery rooms generally do not manage non- inflamed appendix.

\section{Materials and Methods}

This retrospective study was designed in order to explore a new predictor for the early diagnosis of perforated acute appendicitis. A data has been collected about patients diagnosed with acute appendicitis between male and females from the age of 4 up to 80 among king Fahad hospital and East Jeddah hospital during the period from 1st Jan 2012 to 30th July 2017, with sample size of 888 patients $[4,5]$. Data was collected from the records present in the hospital facility and files archives.

Data were analysed using SPSS software version 22 (SPSS $®$ Inc, Chicago, USA). Results were expressed in various tables as counts and frequencies. Discrete variables were compared using Chi-square or Fisher exact test as appropriate [6,7]. A comparison was done for the results of statistical analysis to have a final conclusion of the study. All tests were two-tailed, and a P-value less than 0.05 were deemed to indicate a statistically significant difference [8-10].
From a sample size of 888 subjects, results show that $75.6 \%$ of the samples are Saudi compared to $24.4 \%$ of the sample Non-Saudi, and $69.1 \%$ of the sample are males compared to $30.9 \%$ females [11-13]. When we combine the sample distribution by nationality and gender, results show that $65.1 \%$ of the Saudis are males while $34.9 \%$ are Females. On the other hand, $81.6 \%$ of the Non-Saudis in the sample are Males compared to $18.4 \%$ Females [14].

The average age among the sample is 25.65 years and the median age is 25 years, In addition, the age in the sample was included within the interval of 4 to 75 years. Within the same area, $37.2 \%$ of the sample in the age group from 21 to 30 years old, $22.9 \%$ of the sample in the age group from 15 to 20 years old, 18.2 in the age group from 31 to 40 years old, the age group less than 15 years old have only $12.3 \%$ and the age group more than 40 years old is $9.3 \%[15,16]$.

Open surgery operation was adopted for $88.2 \%$ of the sample while Laparoscopic operation was done for the rest of the sample $(11.8 \%)$. While the diagnosis was one of the following: acute appendicitis (51.8\%), perforated appendicitis (37.5\%) and abscess formation after complicated appendicitis $(10.7 \%)$. The vast majority of the sample was suffering from liver disease with a percentage of 91.7 compared to normal liver disease with a percentage of $8.3[17,18]$. Direct and total bilirubin were measured and the results show that $63.4 \%$ of the patient that the direct bilirubin level observed for them has normal levels of the serum bilirubin (less than $0.3 \mathrm{mg} / \mathrm{dl}$ ) on the other hand $36.6 \%$ of those patient suffering from an elevated levels of the serum bilirubin (more than or equal $0.3 \mathrm{mg} / \mathrm{dl}$ ) while $83.5 \%$ of the patient that the total bilirubin level observed for them the serum level from 0.1 to $1.2 \mathrm{mg} / \mathrm{dl}$, compared to $16.5 \%$ of those patients the serum level is more than $1.2 \mathrm{mg} / \mathrm{dl}$ [19,20]. Approximately the elevation compared to normal levels of direct bilirubin was the same when the comparison was done between Saudis and non-Saudis, females and males and different age groups [21].

Testing all age groups, result of the tests show that the level of bilirubin enzyme (direct bilirubin) is statistically significant with the lab findings of perforated acute appendicitis patients in an ordinal way as the percentage for normal level for the patients suffering from perforated appendicitis was $78.4 \%$ while the rest is abnormal in contrast to acute inflammation and abscess formation groups which are having near percentages less than 0.05 $\mathrm{P}$-value in Chi-square test [22,23]. 


\section{Medical Journal of Clinical Trials \& Case Studies}

However, the findings are showing that regarding total bilirubin the results do not differentiate between different appendicitis cases as the percentages of the three types are having an average of $83.2 \%$ for the readings ranging from 0.1 to $1.2 \mathrm{mg} / \mathrm{dl}$ and the rest are cases with elevated total bilirubin above $1.2 \mathrm{mg} / \mathrm{dl}$. In addition, P-value is above 0.05 upon Chi-square testing which means statistically insignificant difference between different appendicitis types patients' groups [24]. Nevertheless, after stratifying patients according to age, age group of less than 15 years had shown significant difference regarding total bilirubin levels when it was compared between different types of appendicitis. Abscess formation was the least percentage of normal range total bilirubin with a percentage of $0.0 \%$ and the rest of the sample suffering from abscess formation within this age interval had elevated readings. While perforation had an opposite result with a $100 \%$ percentage for normal total bilirubin readings and $0.0 \%$ elevated total bilirubin readings. While in significance results was found for total bilirubin.

\section{References}

1. Attwood SE, Hill AD, Murphy PG, Thornton J, Stephens RB (1992) A prospective randomized trial of laparoscopic versus open appendectomy. Surgery 112(3): 497-501.

2. Adrian E Ortega, John G Hunter, Jeffrey H Peters, Lee L Swanstrom, Bruce Schirmer (1995) A prospective, randomized comparison of laparoscopic appendectomy with open appendectomy. Laparoscopic Appendectomy Study Group. Am J Surg 169(2): 208-212.

3. Martin LC, Puente I, Sosa JL, Bassin A, Breslaw R, et al. (1995) Open versus laparoscopic appendectomy. A prospective randomized comparison. Ann Surg 222(3): 256-262.

4. Frazee RC, Roberts JW, Symmonds RE, Snyder SK, Hendricks JC, et al. (1994) A prospective randomized trial comparing open versus laparoscopic appendectomy. Ann Surg 219(6): 725-731.

5. Mitsugi Shimoda, Tsunehiko Maruyama, Kiyotaka Nishida, Kazuomi Suzuki, Tomoya Tago, et al. (2018) Comparison of clinical outcome of laparoscopic versus open appendectomy, single center experience. Heliyon 4(5): e00635.
6. Hong-Bo Wei, Jiang-Long Huang, Zong-Heng Zheng, Bo Wei, Feng Zheng, et al. (2010) Laparoscopic versus open appendectomy: a prospective randomized comparison. Surg Endosc 24(2): 266-269.

7. Lisa Minné, Dale Varner, Arline Burnell, Ratzer E, Clark J, et al. (1997) Laparoscopic vs Open Appendectomy Prospective Randomized Study of Outcomes. Arch Surg 132(7): 708-711.

8. Tiwari Manish M, Reynoso Jason F, Tsang Albert W, Oleynikov Dmitry (2011) Comparison of Outcomes of Laparoscopic and Open Appendectomy in Management of Uncomplicated and Complicated Appendicitis. Ann Surg 254(6): 927-932.

9. Michael R Cox, John L McCall, James Toouli, Robert T Padbury, Thomas G Wilson, et al. (1996) Prospective Randomized Comparison of Open versus Laparoscopic Appendectomy in Men. World J Surg 20(3): 263-266.

10. Pedersen AG, Petersen OB, Wara P, Rønning H, Qvist $\mathrm{N}$, et al. (2002) Randomized clinical trial of laparoscopic versus open appendicectomy. Br J Surg 88(2): 200-205.

11. Ninh $T$ Nguyen, Kambiz Zainabadi, Shahrazad Mavandadi, Mahbod Paya, C Melinda Stevens, et al. (2004) Trends in utilization and outcomes of laparoscopic versus open appendectomy. Am J Surg 188(6): 813-820.

12. Strzałka M, Bobrzyński A, Budzyński A, Gwóźdź A (2009) Open or laparoscopic appendectomy?. Videosurgery and Other Miniinvasive Techniques 4(3): 110-114.

13. Marzouk M, Khater M, Elsadek M, Abdelmoghny A (2003) Laparoscopic versus open appendectomy: a prospective comparative study of 227 patients. Surg Endosc 17(5): 721-724.

14. Safiyya M Ali, Mazen Hassanain (2011) Laparoscopic Versus Open Appendectomy.

15. Al-Mulhim AS, Al-Mulhim FM, Al-Suwaiygh AA, AlMasaud NA (2002) Laparoscopic versus open appendectomy in females with a clinical diagnosis of appendicitis. Saudi Med J 23(11): 1339-1342.

16. Adnan Merdad (1999) Laparoscopic Versus Open Appendectomy. 


\section{Medical Journal of Clinical Trials \& Case Studies}

17. Addiss DG, Shaffer N, Fowler BS, Tauxe RV (1990) The epidemiology of appendicitis and appendectomy in the United States. Am J Epidemiol 132(5): 910-925.

18. Semm K (1983) Endoscopic appendectomy. Endoscopy 15(2): 59-64.

19. Kai-Biao Lin, Robert Lai K, Nan-Ping Yang, Ke-Shou Wu, Hsien-Wei Ting, et al. (2015) Trends and outcomes in the utilization of laparoscopic appendectomies in a low-income population in Taiwan from 2003 to 2011. Int J Equity Health 14:100.

20. Kazemier G, de Zeeuw GR, Lange JF, Hop WCJ, Bonjer HJ (1997) Laparoscopic vs open appendectomy. Surgical Endoscop 11(4): 336-340.

21. Liping Dai, Jian Shuai (2017) Laparoscopic versus open appendectomy in adults and children: A meta- analysis of randomized controlled trials. United European Gastroenterol J 5(4): 542-553.

22. Katkhouda N, Mason RJ, Towfigh S, Gevorgyan A, Essani R (2005) Laparoscopic versus open appendectomy: a prospective randomized doubleblind study. Ann Surg 242(3): 439-448.

23. Ignacio RC, Burke R, Spencer D, Bissell C, Dorsainvil C, et al. (2004) Laparoscopic versus open appendectomy: what is the real difference? Results of a prospective randomized double-blinded trial. Surg Endosc 18(2): 334-337.

24. Kurtz RJ, Heimann TM (2001) Comparison of open and laparoscopic treatment of acute appendicitis. Am J Surg 182(3): 211-214. 